\title{
AC 2011-1827: ASSESSING TEAMWORK AND BEST EDUCATIONAL PRACTICES IN DIVERSE MULTIDISCIPLINARY PROGRAMS
}

\section{Scott P. Schaffer, Purdue University}

Scott P. Schaffer is an associate professor in the Learning Design and Technology program at Purdue University where he teaches courses related to design, assessment \& evaluation, and learning theory. His research focuses on team learning and the design of informal learning spaces.

\section{Margaret Huyck, Illinois Institute of Technology}

Professor Emeritus; Principle Investigator on NSF project involving four universities engaged in developing measures for teamwork and ethical awareness, and identifying best educational practices for developing those competencies among undergraduate students.

\section{William C. Oakes, Purdue University, West Lafayette}

William Oakes is the Director of the EPICS Program at Purdue University, one of the founding faculty members of the School of Engineering Education and a courtesy faculty member in Mechanical Engineering and Curriculum and Instruction in the College of Education. He is an fellow of the ASEE and NSPE. .He was the first engineer to win the Campus Compact Thomas Ehrlich Faculty Award for ServiceLearning. He was a co-recipient of the 2005 National Academy of Engineering's Bernard Gordon Prize for Innovation in Engineering and Technology Education for his work in EPICS.

\section{Daniel Gandara, Illinois Institute of Technology}

Daniel Gandara holds a masters degree in personnel and human resource development and is currently working towards a Ph.D in Industrial and Organizational Psychology. He currently does consulting work with programs in cross-disciplinary team-based education. His research interests are in the areas of team development, team training and learning, team assessment, counterproductive team behaviors, dysfunction in teams, and team-based performance and management. 


\section{Assessing Teamwork and Best Educational Practices in Undergraduate Multidisciplinary Teams}

\section{Background}

Assessing how well undergraduate students recognize and think about teamwork issues that arise in their emerging professional practice has proven to be a significant challenge. The evidence is clear that many students will be working on multi-disciplinary or cross-functional teams, within and outside of engineering, as a professional. However, it is a challenge to prepare them for this eventuality while developing their disciplinary identification and expertise. Many students are still developing expertise within their own discipline or profession; thus, requiring them to work effectively on a multi-disciplinary team creates special challenges. Assessment of team learning requires a measurement process to identify the practices most likely to result in enhanced awareness of professional teamwork issues, and team members' ability to behave in effective ways. Progress made by one research team toward developing cross-disciplinary team learning assessment measures appropriate for use in institutions that have a major focus on project-based and team-based learning experiences is described in this paper. Specific lessons learned from four programs at four institutions that employ experiential learning with multidisciplinary teams are also shared.

\section{Assessment Instruments for Teams}

One clear inspiration for the educational priorities addressed in this project are the ABET criteria that have evolved over the past decade, particularly the focus on professional skills recognized as essential in the successful practice of engineers ${ }^{1}$. These attributes have been expanded by the National Academy of Engineering's report on the attributes of the engineer of $2020^{2}$. While our programs address many of the professional competencies, this proposal is focused on one that appears in both the ABET criteria and also the NAE's report: interdisciplinary team competencies. Over the past several years, the partner institutions have developed a number of processes and tools to assess accomplishment of learning objectives at the individual and team level, and we are also assessing strategies for improving our program performance ${ }^{3,4,5}$. Our goal is to work toward authentic and direct measures of the complex competencies we are seeking to develop.

An overarching goal of this study was to develop measures of team learning and functioning appropriate for use in a variety of team contexts at the university and professional level. More specifically, our research addresses the challenges of learning and working on multidisciplinary project teams, specifically design project teams. The increasingly complex and global marketplace we live in requires that pre-professionals in engineering, science, technology, and social science fields learn how to work in cross-disciplinary and trans-disciplinary ways. Multidisciplinary undergraduate team projects are ubiquitous in higher education, however, projects all too often result in less effective learning experiences or missed opportunities relative to learning how to work collaboratively. Reasons for this are that methods for assessing and providing feedback to students relative to team learning are not well developed and are challenging to implement. 
In response to this opportunity, we have designed, developed, and evaluate targeted assessment strategies that specifically focus on improving team learning and performance practices. Four university programs are described with reference to the team assessment measures deemed appropriate within each context. Assessment measures developed include a cross-disciplinary team learning (CDTL) self-efficacy; a survey of cross-disciplinary functioning; and a survey of counter-productive team behaviors. Conceptually, these instruments attempt to measure individual learning and performance behaviors relative to team work rather than measuring structural aspects of the teams (rewards, composition, tasks). Structural variables are considered mediating or moderating variables in this research while individual learning behaviors are outcome variables.

Validating measures of team functioning and team learning across the four partner institutions has proven to be a formidable task and our research collaborative has attempted to create a data set that is most useful at the programmatic level. Ideally, data collected across diverse settings will allow the fusing of programmatic, team, and individual levels of data related to team functioning and learning. Our goal for all measures is to demonstrate both reliability and validity by utilizing accepted psychometric procedures.

The 16-item Cross Disciplinary Team Learning Efficacy scale (CDTL efficacy scale) was developed based on a conceptual model developed in earlier works by members of the research team $^{6}$. This instrument attempts to measure individual team member confidence for learning behaviors related to working on a team. Four factors initially proposed to measure CDTL include: identification of ones' own skills/knowledge, awareness of others' skills/knowledge, deep discussion of design issues across discipline areas, and integration of design discussions as represented by design products. Two waves of data were collected with undergraduate students participating in Engineering Projects in Community Service (EPICS) teams in spring 2010, yielding 257 completed surveys and 112 pairs of pre and post self-reported data. The data contain self-reported CDTL efficacy as well as information on individual background, team processes and outcomes. Data analysis aims at three important issues at the individual level: 1) validation of the CDTL efficacy scale, 2) assessment of the nature of change in individual CDTL efficacy, and 3) exploration of factors that explain the change in individual CDTL efficacy. Factor analysis was conducted to assess the factor structure of the CDTL efficacy scale and the reliability of each factor. A reliable three-factor CDTL efficacy scale emerged. The three factors include identification (identifying the relevance of one's own disciplinary expertise to the design project), recognition (recognizing the relevance of others' disciplinary expertise in design discussions), and integration (engaging in productive communication with teammates to integrate different disciplinary expertise in the design outcome).

An overall statistically significant improvement in self-reported individual CDTL efficacy when comparing individual self-report at the beginning and the end of the spring semester was found, with substantial variation across individuals. Specifically, while $66 \%$ of the participants reported increased CDTL efficacy, the other $34 \%$ reported either no change or decreases in CDTL efficacy. A multi-level model was then developed to explain changes in individual CDTL efficacy with individual background, task characteristics, team composition, and team processes. 
a. In terms of individual background, more senior undergraduate students reported greater improvement in efficacy for CDTL while students with more experience participating in EPICS teams reported lower levels of improvement.

b. In terms of task characteristics, students working on design tasks involving more design phases reported lower levels of improvement. In terms of team composition, disciplinary diversity seems to be associated with lower levels of improvement in individual CDTL efficacy, while gender diversity has a marginally significant positive association with improvement in CDTL efficacy.

c. Finally, individuals working in teams with higher levels of intra-team learning behaviors reported higher levels of improvement.

The above results are tentative as we have a fairly small sample size: 112 individuals nested within 31 teams. In addition to increasing sample size, we plan to link CDTL efficacy to important individual and team outcomes with a view to assess the extent to which CDTL efficacy matters within multidisciplinary teams.

Furthermore, a 20-item Cross Disciplinary Functioning Survey (CDFS Performance Scale) was developed from the results of a task and competency analysis. The analysis helped ascertain commonalities in the competencies and behaviors that any student in any team would engage in despite the unique problems encountered by individual teams. Four different collections have resulted in 365 completed surveys. This battery assesses the activities that are core to effective performance within a cross-disciplinary team. The components of the battery were derived using exploratory factor analytic procedures which produced four highly reliable factors. These four factors include research skills (the ability to gather primary and secondary evidence to inform decisions), interpersonal management (the ability for individuals to interact with others), trust (an individual attitude that describe the confidence that other members are able and willing to perform assigned tasks), and project management (the teams ability to plan, organize, and direct resources of the team to reach a desired outcome). Evidence currently supports this measure's ability to predict other indicators of team performance. Performance data collected at the team level includes project plan scores, midterm, and final presentation scores. From the results of this battery a course using a skills-based approach to team-learning was developed.

An 11-item measure of counterproductive team behaviors has also been developed. The measure was developed from an integration of other similar measures used to assess these types of behaviors in the workplace. Three different collections have resulted in 321 completed surveys. A factor analysis yielded two interpretable components that provide evidence that students direct counterproductive behaviors either toward other individuals within a team or to the team in general. Such behaviors include psychological withdrawal, passive productive deviance, sabotage/theft, and incivility. Evidence shows these behaviors to be related to characteristics of the team's leadership and shared attitudes.

Future validity studies are planned and include conducting a confirmatory factor analysis to test whether the measured constructs are consistent with our understanding of the nature of these constructs and further criterion-related validation to better understand the predictive ability of these measures to important learning, performance, and program outcomes. 


\section{Best Practices}

The four university partners in this NSF CCLI Phase 2 project share key characteristics: all have undergraduate engineering programs with multidisciplinary teams, all support 25-40 teams per semester, all have learning activities related to teams and include teamwork as part of their learning objectives for their design experiences. Each program, however, also has distinct features, as described below.

Engineering Projects in Community Service (EPICS), a program in Purdue University's College of Engineering, offers an innovative service-learning approach to teaching design where multidisciplinary teams of students partner with local community organizations to identify, design, build, and deliver solutions to meet the community's needs (reference that identifies the program). The goal of EPICS is to meet a critical educational need by providing hands-on engineering and technical design opportunities to a broad group of students, especially females and underrepresented minorities. The program also meets vital needs within the communities it serves by providing not-for-profit organizations such as community service agencies, schools, museums, and local government office with the resources they often need but cannot access. Each team is constituted for several years, from initial project definition through final deployment, allowing for projects of significant design complexity and high potential impact in the community. The designs produced by EPICS teams address compelling issues in the local community that often have potential applications in other communities through dissemination or commercialization. The success of the EPICS program motivated the NSF funded dissemination to a consortium of institutions that have adopted EPICS to their own campuses. Currently, 21 schools are part of the EPICS University Consortium. More recently, EPICS has been adapted to a high school format that is being used in schools in seven states and by IEEE abroad. These networks will provide built-in dissemination vehicles for the results of the project.

The Illinois Institute of Technology's IPRO Program has the broadest scope of projects of the four collaborating institutions, covering service learning, entrepreneurship, and process improvement, and product/venture development. Every undergraduate student at IIT is required to participate in two IPRO projects as part of their General Education requirement. Students select projects, though some projects now require an application and approval process. IPRO project teams are composed primarily of junior \& senior undergraduate students across a range of majors (engineering, computer science, architecture, sciences, business, psychology, social sciences and humanities). During the fall semester of 2007, over 375 students participated in 37 multidisciplinary teams (each with a minimum of three majors represented). IIT is a private university in Chicago, Illinois, with roughly 2,300 undergraduate and 4,500 graduate students, with $18 \%$ minority and a substantial $[34 \%+]$ international student body. IPRO was initiated in 1995 with NSF funding.

Lehigh University has the Integrated Product Development (IPD) program within the P.C. Rossin College of Engineering and Applied Science. Lehigh is a private university located in Bethlehem, PA, with 4,600 undergraduate students and 2,000 graduate students. The IPD program was founded in 1994. It provides juniors, seniors and graduate students the opportunity to work in interdisciplinary teams with industrial sponsors to design, fabricate and produce new products for a global economy. At the undergraduate level, draws students enrolled in Bio- 
Engineering, Mechanical Engineering and Mechanics, Material Science Engineering, Design Arts, and various business majors. About 150 students are distributed on 25 teams per semester with projects from industry sponsors, local entrepreneurial startups and student startups. The IPD team has been active with the ASEE and USASBE as well as several entrepreneurship oriented foundations such as the NCIIA, Kern Family Foundation and Kauffman Foundation.

Michigan Technological University has the Enterprise Program, initiated in 1998 with funding from NSF to create an undergraduate curriculum that incorporates active and discovery-based learning. Michigan Tech is a public university, located in Houghton, Michigan, with 6,500 students of whom 3,600 are in the college of engineering. The Enterprise Program recruits students from second year through seniors to participate in teams that operate like a company to solve real-world problems by performing testing and analysis, making recommendations, developing projects, providing services, meeting budgets and managing multiple projects. The Enterprise Program has grown to include 25 different teams, with 700 students participating, and representation from 25 different disciplines.

While these four programs share the fundamental characteristics of having multi-disciplinary team-based design courses, the diversity across the institutions also represents the richness of cultures found within engineering. Throughout our research, this richness constantly and significantly informed the path of development and led to a deeper understanding of both the complexity and the importance of teaching teaming, leadership and cross-disciplinary learning. Several best practices related to supporting cross-disciplinary learning were identified during across the programs. Brief descriptions of some of these practices include:

1. The collaboration process between the programs exhibited a valuable best practice. The four programs that have worked together have a strong desire to continue to work together to develop assessment tools and instructional methods that work across programs, and to continue to create synergies related to the strength of the partnership.

2. It takes time and effort to get to know the languages of the others. As evidence of appreciating and understanding language as a best practice, the programs have learned to provide as much of the instructional materials as possible in discipline-neutral language to provide a more level playing field for all majors. Students from outside of engineering know that they are signing up for an engineering-centered class as each school. Providing ways to communicate to each major that their skills are important and valued is important.

3. Integrating ABET outcomes with the outcomes expected from the other colleges on campus is a best practice [7]. An example of this is the EPICS Program that took the ABET outcomes and replaced "engineering" with "your discipline" and "technical" with "disciplinary". These outcomes then become appropriate for all the participating disciplines.

4. Faculty development is another important practice across the programs. Mentoring multidisciplinary teams can be intimidating for faculty and having a development program is needed to be successful ${ }^{8}$. All of the programs have specific and direct approaches for supporting faculty in understanding how to work with multidisciplinary teams. 
5. Design for others is a best practice relates to the stakeholders and partners that teams work with. All of the programs see design for others as a very appropriate space to do multidisciplinary teaming ${ }^{9}$.

6. Continuous peer assessment as formative feedback and for grading is a best practice. The programs differ on their emphasis of individual, team, and client in peer assessment and evaluation but they all see this form of assessment as integral to cross-disciplinary learning.

\section{Toward a Framework for Best Practices}

Best practices for multidisciplinary project team learning and performance may be thought of from the perspective of both the program and the learners or more precisely the interaction between the two ${ }^{10}$. The program perspective includes structures, processes, and outcomes intended to help learners and the program accomplish goals. The learner perspective includes specific strategies intended to facilitate individual and team learning related to working as an effective team member and team. It is extremely difficult to untangle the mutual influences of program, team, and individual on learning but it is useful to think of these units of analyses as spheres of influence on outcomes ${ }^{11}$. Examples of each system level this evaluative framework include:

\section{Program level}

\begin{tabular}{|l|l|l|}
\hline Structures & Processes & Outcomes \\
\hline $\begin{array}{l}\text { The program has an external } \\
\text { orientation as well as a } \\
\text { university focus. }\end{array}$ & $\begin{array}{l}\text { Partners in the community } \\
\text { provide projects, mentoring, } \\
\text { critical analysis of projects. }\end{array}$ & $\begin{array}{l}\text { Benefits to the community } \\
\text { create a culture of learning } \\
\text { and promote sustainability. }\end{array}$ \\
\hline $\begin{array}{l}\text { The program focuses on a } \\
\text { skills based approach to team } \\
\text { development, engagement } \\
\text { and problem-solving. }\end{array}$ & $\begin{array}{l}\text { Instructors help develop the } \\
\text { requisite skills in the } \\
\text { formative stages of team } \\
\text { development to move teams to } \\
\text { a stage of higher learning and } \\
\text { performance. }\end{array}$ & $\begin{array}{l}\text { Teams are better prepared } \\
\text { to address complex } \\
\text { problem solving issues and } \\
\text { have a richer appreciation } \\
\text { of other discipline's } \\
\text { approach to problem } \\
\text { solving. }\end{array}$ \\
\hline
\end{tabular}

\section{Team level}

\begin{tabular}{|l|l|l|}
\hline Structures & Processes & Outcomes \\
\hline $\begin{array}{l}\text { Multidisciplinary teams focus } \\
\text { on client and stakeholder } \\
\text { requirements. }\end{array}$ & $\begin{array}{l}\text { Team designs are critiqued by } \\
\text { internal and external } \\
\text { stakeholders. }\end{array}$ & $\begin{array}{l}\text { Team interactions are } \\
\text { complex to understand and } \\
\text { manage and require a } \\
\text { variety of skills. }\end{array}$ \\
\hline $\begin{array}{l}\text { Multidisciplinary teams } \\
\text { create their own team best- } \\
\text { practices. }\end{array}$ & $\begin{array}{l}\text { Facilitators engage the team in } \\
\text { brainstorming activities to } \\
\text { help define the causes and } \\
\text { effects of team engagement. }\end{array}$ & $\begin{array}{l}\text { Instructors, team leaders } \\
\text { and members learn the } \\
\text { consequences of team } \\
\text { engagement. }\end{array}$ \\
\hline Multidisciplinary teams learn & Teams learn the signs and & Teams learn to be aware \\
\hline
\end{tabular}




\begin{tabular}{|l|l|l|}
\hline $\begin{array}{l}\text { both positive and negative } \\
\text { attributes of teams. }\end{array}$ & $\begin{array}{l}\text { reasons why a team's structure } \\
\text { can begin to go bad. }\end{array}$ & $\begin{array}{l}\text { and avoid negative } \\
\text { behaviors that are } \\
\text { damaging to the teams } \\
\text { ability to learn and } \\
\text { perform. }\end{array}$ \\
\hline
\end{tabular}

\section{Individual level}

\begin{tabular}{|l|l|l|}
\hline Structures & Processes & Outcomes \\
\hline $\begin{array}{l}\text { Teams create rules, roles and } \\
\text { project plans. }\end{array}$ & $\begin{array}{l}\text { Individuals are responsible for } \\
\text { making their understanding of } \\
\text { team goals explicit. }\end{array}$ & $\begin{array}{l}\text { Individuals seek information, } \\
\text { share knowledge, adapt to } \\
\text { challenges, discuss how to } \\
\text { solve problems. }\end{array}$ \\
\hline $\begin{array}{l}\text { Identifying strengths, needs, and } \\
\text { expectations for the project and } \\
\text { course. }\end{array}$ & $\begin{array}{l}\text { Individuals write, share, and } \\
\text { reflect on their knowledge, skills, } \\
\text { and abilities with other team } \\
\text { members. }\end{array}$ & $\begin{array}{l}\text { Individuals develop their } \\
\text { cognitive, behavioral, and } \\
\text { attitudinal competencies for } \\
\text { team learning. Tasks are } \\
\text { aligned with the inherent } \\
\text { strengths of the team. }\end{array}$ \\
\hline
\end{tabular}

\section{Summary}

Various strategies are being employed by the different programs to enhance cross-disciplinary teamwork. Some of the programs have specific class or lecture modules. One of the programs has an experimental program involving ongoing teamwork exercises; their measures will be compared with those in the regular program that does not include such an emphasis. Some programs have had students writing reflections that include questions about the teamwork issues encountered by the team. These different strategies will provide the conditions under which learning outcomes were achieved and related to various cross-disciplinary team measures developed by the research group. The correlation research design paradigm affords opportunities to compare outcomes associated with varied instructional design strategies and elicits practices to enhance their effectiveness at the team and program levels. The development of best practices informs and provides richness to the quantitative data. Ongoing cross-case analysis of structural, process, and outcome data across the program, team, and individual levels will help to guide implementation and dissemination of the instruments and the practices in similar programs across the world.

\section{Acknowledgements}

This research is funded by the National Science Foundation, CCLI grant \# 0817531. Any opinions, findings, and conclusions or recommendations expressed in this material are those of the authors and do not necessarily reflect the views of the National Science Foundation. 


\section{References}

[1] ABET (2005). Criteria for accrediting engineering programs effective for the evaluations during the 2006-2007 accreditation cycle. The Engineering Accreditation Board for Engineering and Technology. http://www.abet.org/eac/eac/htm.

[2] National Academy of Engineering (2005). Educating the Engineer of 2020: Adapting Engineering Education to the New Century, Washington D.C.:National Academy Press.

[3] Schaffer, S., Chen, X., Oakes, W. (2010). Measuring cross-disciplinary team learning in undergraduate project design teams. November 2010 40th Annual Frontiers in Education Conference, Washington D.C.

[4] Ferguson, D. F., Huyck, M.H. \& George, S. (2007). Continuous process improvement in attaining learning objectives. Proceedings of the ASEE National Conference, Honolulu, Hawaii

[5] Getzler-Linn, Lisa, Ochs, John B. and Watkins, Todd A (2006, January). Program and Student Performance Assessment in Team-Based Project Courses with Focus on Technical Entrepreneurship and Product Development: Lehigh University's IPD Program. Proceeding of the USASBE conference, Phoenix Arizona.

[6] Schaffer, S, Lei, K, \& Reyes, L, "A framework for cross-disciplinary team learning and performance", Performance Improvement Quarterly, Vol 21, No 3, 2008, pp. 7-21.

[7] Felder, R., \& Brent, R., "Designing and teaching courses to satisfy the ABET engineering criteria", Journal of Engineering Education, Vol 21, No 1, 2003, 7-26.

[8] Fruchter, R. \& Lewis, S., “ Mentoring models in an a/e/c global teamwork e-learning environment”, American Society for Engineering Education Annual Conference and Exposition, 2001, p. 12.

[9] Mills, J., \& Treagust, D., "Engineering Education:Is Problem-Based or Project-Based Learning the Answer?" Australasian Journal of Engineering Education, Vol 3, 2003, pp. 2-16.

[10] Borrego, M., \& Newswander, L. K., "Characteristics of Successful Cross-disciplinary Engineering Education Collaborations", Journal of Engineering Education, Vol 97, No 2, 2008, pp. 123-134. [11] Richter, D., \& Paretti, M., "Identifying barriers to and outcomes of interdisciplinarity in the engineering classroom", European Journal of Engineering Education, Vol 34, No 1, 2009, pp.29-45. 